\title{
AN UNUSUAL CAUSE OF GENERALIZED SWELLING
}

\author{
SHAHRIN $\mathrm{S}^{1}$, ISLAM MA ${ }^{2}$, KHAN MEU ${ }^{3}$, AHMED PI $^{4}$, ISLAM MN ${ }^{5}, \mathrm{CHOWDHURY}^{6}$
}

\begin{abstract}
:
Amyloidosis and multiple myeloma are included in the same spectrum of clonal plasma cell disorder. Amyloidosis can present with localized deposits or manifest as systemic disease involving multiple organs such as kidney, heart, intestine. Free Ig subunits, mostly light chains secreted by a single clone of B cells, are the cause of the most frequent and severe amyloidosis affecting the kidney. The incidence of AL amyloidosis is nine per 1 million populations per year. Amyloid deposists are found in approximately 10\% of all patients with myeloma and in 20\% of those with pure light chain myeloma[1]. Here we are reporting a case who initially presented with generalized swelling and subsequently found to have AL amyloidosis involving multiple organs due to multiple myeloma.
\end{abstract}

J Dhaka Med Coll. 2017; 26(2) : 173-177

\section{Case Report:}

A-55-Year non diabetic, non hypertensive male presented to our department with generalized swelling associated with decreased urinary output for last 3 months. He also complained about productive cough with sputum for the same duration. His swelling first appeared in the face then become generalized.Patient also complaints of weight loss which is around $10 \mathrm{~kg}$ within the time period. Regarding the cough of this patient, it was productive in nature, yellowish in colour and was never mixed with blood. Cough was not associated with chest pain, or fever. Patient did not give any history of long standing joint pain, rash, previous history of TB or exposure to TB patient.His bowel and bladder habit was normal.
Patient gave no significant past history. He was a smoker around 24 packs per year and was non alcoholic. There was no history of such disease running in the family. He came from a low socio economic background and not allergic to any drugs.

General examination of the patient revealed mild anaemia, bilateral pedal edema, supraclavicular enlarged lymph nodes, his Heat coagulation test was +++. Chest auscultation revealed vesicular breath sound with bilateral basal crepts which are biphasic, coarse, not alters with cough. Abdominal examination revealed hepatomegaly of $4 \mathrm{~cm}$ with a firm consistency and smooth surface. Cardiovascular system revealed no abnormality.

1. Dr. Sabrina Shahrin, FCPS Nephrology Trainee, Dhaka Medical College

2. Dr. Md. Aminul Islam, Transplant coordinator (Nephrology), Dhaka Medical College

3. Dr. Md. Ehsan Uddin Khan, Indoor Medical Officer (Nephrology),

4. Dr. Parvez Iftekhar Ahmed: Associate Professor (Nephrology), Dhaka Medical College

5. Dr. Md Nazrul Islam, Associate Professor (Nephrology),Dhaka Medical College.

6. Dr. Md Nizamuddin Chowdhury, Professor (Nephrology), Dhaka Medical College.

Correspondence : Dr. Sabrina Shahrin, FCPS Nephrology Trainee, Dhaka Medical College

Received: 21 May 2017

Revision: 01 July 2017

Accepted: 01 September 2017

DOI: http://dx.doi.org/10.3329/jdmc.v26i2.38839 


\begin{tabular}{ll}
\hline INVESTIGATION & \multicolumn{1}{c}{ TEST RESULT } \\
\hline Urine R/E: & Protein +++ RBC nil. \\
CBC & Hb-8.9 g/d1,WBC-16.37 thousand/mm3, Platelet-4 lac 55 \\
& thousand.Neut-79.4\%,L-15.7\%,M-4.1\%,E-0.2\%.ESR-42. \\
Combined deficiency anemia. & \\
PBF: & $0.7 \mathrm{mg} / \mathrm{dl}$ \\
Serum creatinine: & $2.9 \mathrm{gm} / \mathrm{dl}$ \\
Serum Albumin: & Serum bilirubin-0.5 mg/dlAST-20 U/LALT-14U / LAlkaline \\
Liver function test: & phosphatase-217U/LPT-14.7 sec. \\
& $4.9 \mathrm{IU} / \mathrm{LFT} 4-1.02 \mathrm{gm} / \mathrm{d} 1$. \\
Thyroid Function Test & $9.8 \mathrm{gm} / \mathrm{day}$ \\
UTP for 24 hours & $65.9 \mathrm{gm} / \mathrm{dl}$ \\
Serum total protein & Normal \\
Serum C3,C4 & Negative \\
HBsAg,AntiHCV & $7.9 \mathrm{mg} / \mathrm{dl}$ \\
Serum corrected calcium & $0.8 \mathrm{mg} / \mathrm{dl}$ \\
Serum Magnesium & $6.7 \%$ \\
HbA1c & 345.5 \\
Serum BNP &
\end{tabular}

His investigation profile shows:

$\begin{array}{ll}\text { USG of whole abdomen } & \begin{array}{l}\text { Mild hepatomegaly.RK-12.8 } \\ \text { definedPortal vein diameter } 10 \mathrm{~mm} .\end{array} \\ \text { CXR P/A view } & \text { Mild right sided pleural effusion. } \\ \text { HRCT of chest } & \begin{array}{l}\text { Right sided mild pleural effusion. Sub pleural consolidation. Scattered } \\ \text { inflammatory lesion.Multiple small sub pleural bullae.Calcified } \\ \text { mesenteric lymph node.Cardiomegaly. }\end{array} \\ & \text { Anterior- inferior MI. Low voltage ECG. } \\ \text { ECG } & \text { EF-65\%.No wall motion abnormality. Moderate pulmonary hypertension. } \\ \text { Echo } & \text { Negative } \\ \text { Sputum for AFB } & \end{array}$

After getting these reports we have done coagulation profile of this patient, which was normal. Then patient undergone renal biopsy which showed homogenous eosinophilic material deposition in the glomerulus and messangium. The final comment was features suggest the possibility of LCDD, kappa , lambda immunostain was recommended. We started to look for plasma cell dyscrasia and we did X ray skull (which was normal),X ray KUB which showed left renal stone. His protein electrophoresis showed monoclonal gammopathy. His lymph node biopsy showed Granulomatous lesion without any caseous necrosis with severe amyloid deposition suggestive of TB with Amyloidosis. Ultimately his bone marrow biopsy was done and it showed -Plasma cells are increased in number and around $60-65 \%$ of bone marrow nucleated cells are normal and abnormal plasma cells. Most of them are large blastoid cells, few flaming cells, some are arrange in cluster. Features suggestive of plasma cell dyscrasia, probably multiple myeloma. Immunoelectrophoresis showed IgG lambda subtype of light chain .

As the patients ECG showed ant. Inf. MI, without any wall motion abnormality and with low voltage, so we think about cardiac involvement by amyloidosis. We have done repeat Echo with the consultation of cardiology 
department. This time the Echo showed -mild concentric LV and RV hypertrophy, dilated LA , RA and IVC. Mild MR and TR.PASP-32mm of Hg. No regional wall motion abnormality. Interatrial and interventricular septum are intact.LV diastolic dysfunction (G-II).Good LV systolic function(EF-55\%). Mild RV systolic dysfunction. Elevated LV end diastolic pressure. Findings suggestive of early Restrictive Cardiomyopathy (may be cardiac amyloidosis). Myocardial echopattern was mildly granular.

Considering all the reports, our final diagnosis became as AL amyloidosis involving the kidney, heart and lymph nodes due to Multiple Myeloma.
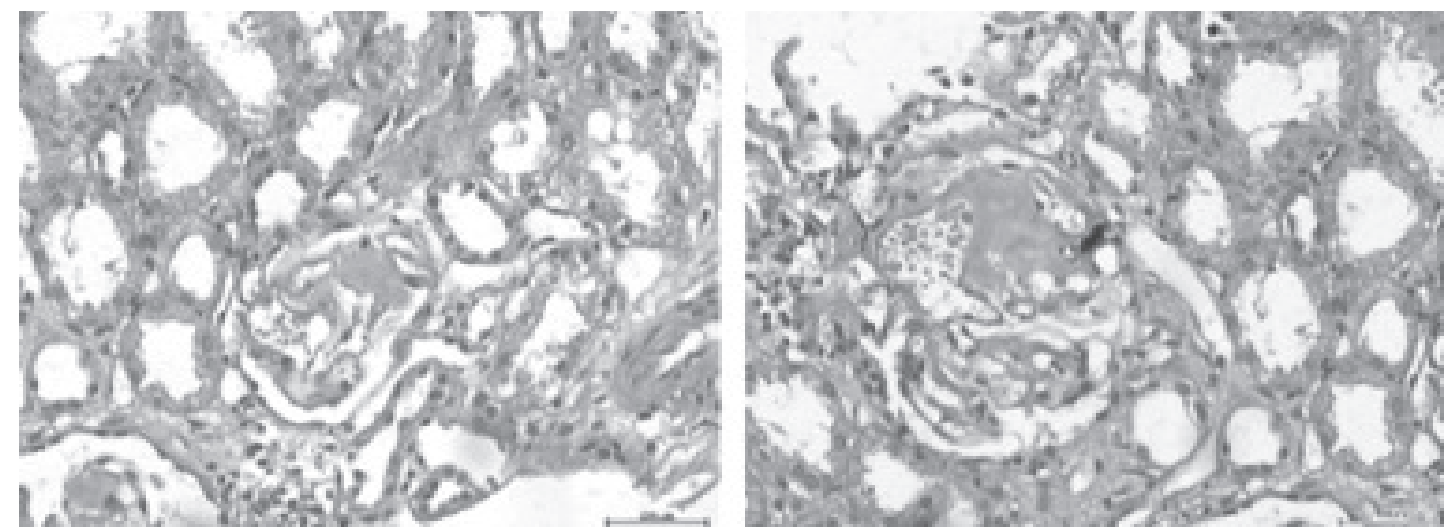

Fig. Light Microscopy Panel of Renal Tissue
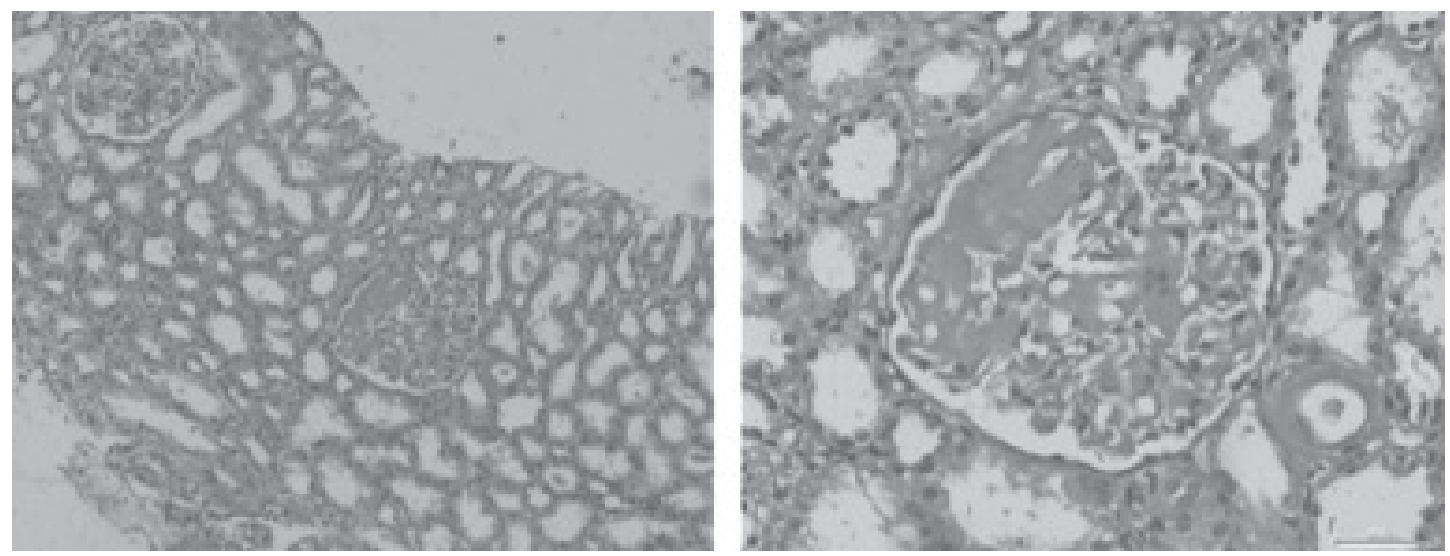

Fig. Congo Red Staining of Renal Tissue
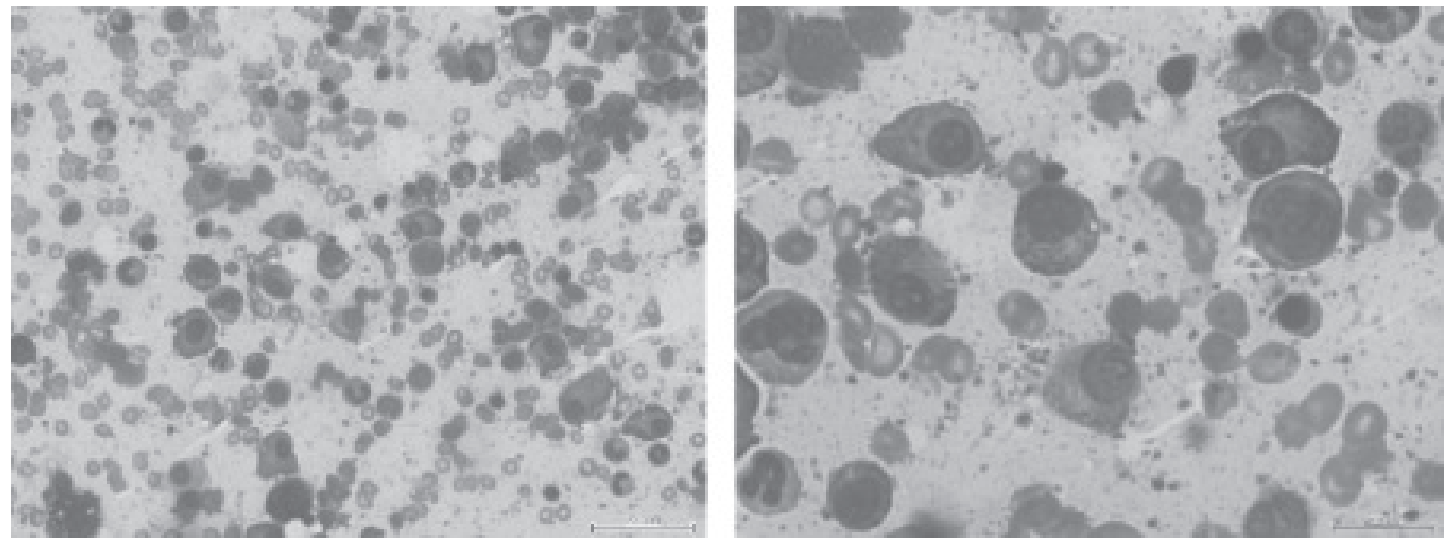

Fig. Bone Marrow Study

The light microscopy panel shows severe amyloid deposition in the glomerulus and messngium, distorting the shape of glomerulus. Congo Red staining of the same tissue shows that it was strongly positive for amyloid.Lastly, the bone marrow slides shows heavy infiltration of plasma cells. 


\section{Discussion:}

The glomerular capillaries are a favourite site for the deposition of abnormal protein ${ }^{1}$. While description of patients with presumed amyloidosis can be traced back to 1639 , the term amyloidosis was coined in 1838.Amyloid (Latin for 'starch like') was introduced to medicine by Rudolf Virchow in 1854, reflecting his misconception of the amorphous extracelluar deposits as starch based, but found later to a fibrillary protein ${ }^{2}$.

There are 3 major type of amyloidosis: primary, secondary and hereditary amyloidosis. Primary amyloidosis, the most common form is a plasma cell disorder that affects mostly the bone marrow, but is not associated with other disease. The build up of amyloid protein primarily affect the heart, kidneys, lungs, tongue, nerves and intestine. It may occur in association with multiple myeloma.

Secondary amyloidosis occurs in association with chronic inflammatory or infectious disease. Hereditary or familial amyloidosis is rare and the only inherited form of the disease ${ }^{3}$.

Our patient is an elderly 55 years old gentleman who presented to us with the complaints of generalized swelling, cough and weight loss for 3 months. Ultimately his renal biopsy revealed amyloidosis with no immunoglobulin deposition. His protein electrophoresis showed a monoclonal spike in the gamma globulin region. Heavy plasma cell infiltration was found in bone marrow biopsy around 60-65\%.The pictures of the renal biopsy and bone marrow biopsy are given.

Though this patient did not showed any CRAB features (hypercalcaemia, renal dysfunction, anaemia, bony lytic lesions), his bone marrow findings was enough for the diagnosis of multiple myeloma.

This patient also had hepatomegaly. His liver span was $15 \mathrm{~cm}$ by USG. Alkaline phosphatase level was also high around 217. The diagnostic criteria for hepatic amyloidosis are liver span above $15 \mathrm{~cm}$, or serum alkaline phosphatase is more than 1.5 times of the institutional upper limit of the normal ${ }^{2}$.Hepatic amyloidosis can also cause non cirrhotic portal hypertension ${ }^{1}$.
Though we had suspicion for hepatic amyloidosis but we could not prove it, as the patient was unwilling to do any invasive procedure.

He also had early features of Restrictive cardiomyopathy, as he had bi-atrial enlargement and high BNP level. Current diagnostic criteria for diagnosisng RCM due to amyloidosis is mean left ventricular wall thickness (septum plus wall thickness divided by 2), greater than 12 on the absence of other explanation[2].Our patient had mean left ventricular wall thickness of 13 $\mathrm{mm}$, but the hallmark of cardiac amyloidosis 'speckled pattern' of myocardium was absent. For further confirmation cardiac MRI was suggested ,but the patient could not afford it.

We have also checked for thickened nerve and postural hypotension, which were absent in our patient.

Now he is getting treatment for MM-the Bortezemib, Dexamethasone, and Cyclophosphamide regimen.

$\mathrm{MM}$ is a common hematological malignanacy representing $10-15 \%$ of all hematologic neoplasm ${ }^{4} .10 \%$ of the patients of multiple myeloma develop systemic light chain amyloid disease ${ }^{5}$. However AL amyloidosis can occur without plasma cell dyscrasia ${ }^{6}$. In one study of 494 cases of primary systemic amyloidosis, $13 \%$ were associated with MM., other monoclonal gamopathy were also associated, specifically monoclonal gammopathy of undetermined significance and smoldering myeloma in $15 \%$ and $3 \%$ of cases respectively 6 .

Amyloidosis can affect all the major organ system of our body like-cardiovascular, renal, nervous system, gastrointestinal, musculoskeletal, integumentary etc. Among them congestive cardiac failure, increased septal thickness, urinary light chains, hepatomegaly, major weght loss are the poor prognostic marker ${ }^{6}$.

AL amyloidosis carries the poorest prognosis of systemic amyloidosis syndrome. Median survival is an average of 43 months for primary systemic amyloidosis ${ }^{6}$.

Multiple myeloma in association with primary systemic amyloidosis is a rare presentation, 
specially when the amyloidosis involves multiple organs. Unfortunately our patient had some bad prognostic markers (cardiac involvement, hepatomegaly, weight loss) as well as high plasma cell load in the marrow, so there is a high chance of cast nephropathy during treatment.We have started the treatment recently, and are waiting to see the result.

In summary AL amyloidosis is an uncommon disorder which may occur in association with multiple myeloma and involve multiple organs as in our case[8]. So whenever a biopsy material shows amyloid deposition we should think about the possible cause and should have a search for it,for the better treatment planning of the patient.

\section{References:}

1. Comprehensive clinical nephrology. Johnson JR, Feehally J, Foege J. Fifth edition, page 317-328.

2. Muchtar E,Buadi KF, Dispenzieri A, Gertz AM. Immunoglobulin light chain amyloidosis :from basics to new developments in diagnosis, prognosis and therapy. Actahaematol 2016,135:172-190.
3. Karadurmas N, EhrturkI, Cakar M, Altun B, Saglam K, Arpaei F. Respiratory medicine CME 4(2011) 131132.www. Elsevier.com/ locate/rmedc.

4. Menadale S, Patel P, Lindgren V, RondelliD, Gaitonde S. Co existent systemic amyloidosis, Multiple myeloma and refractory anaemia with ringed sideroblast in a previously untreated patient. International journal of case reports and images, vol. 2, No 2, February 2011.

5. Arous S, Bensahi I, Noureddine M, Habbal R (2015).A typical case of a multiple myeloma revealed by cardiac amyloidosis.Angol 3:163.

6. Mason RA, RackoffJME, Pollock BR. Primary systemic amyloidosis associated with multiple myeloma:A case report and review of the literature. Cutis 2007; 80: 193-200.

7. BhattyA.S, Siddique SA, Talib A, Mahmoud K, Naqvi I, Khan NA, SaiyedANM. Amyloidosis with multiple myeloma presenting with acromegalicfeatures. Journal of the college of physician and surgeons of Pakistan 2015. vol 25. S112-114.

8. Lisznianski P, Nowak P, Nowak J. Patients with multiple myeloma and suspected cardiac amyloidosis. Journal of rare cardiovascular disease 2015; 2(2) 56-59. 